\title{
AVALIAÇÃO INSTITUCIONAL: SOCIALIZAÇÃO DO ESTUDO NO MUNICÍPIO DE ESCADA/PE
}

http://dx.doi.org/10.5902/2318133826115

\author{
Aldemir Lima da Silva Junior \\ Faculdade Escritor Osmar da Costa Lins, Brasil. \\ Valderês Conceição do Monte \\ Faculdade da Escada, Brasil.
}

\begin{abstract}
Resumo
Este estudo se relaciona com o tema avaliação institucional, em especial com as ações desenvolvidas pelo gestor da Secretaria Municipal de Educação e pelos gestores escolares do município da Escada/PE frente aos resultados do Saepe 2014. Nossa hipótese é que a rede municipal de educação de Escada/PE, diante dos resultados do Saepe 2014, parece não promover ações sistemáticas e contínuas nas escolas. A abordagem é qualitativa, tipo descritiva e foi realizada na Secretaria Municipal de Educação e em duas escolas públicas. Os sujeitos foram dois gestores escolares, a gestora municipal e uma técnica educacional. Os instrumentos de coleta de dados foram análise documental e entrevista semi-estruturada. Os resultados apontaram que os gestores não têm ações frente ao resultado do Saepe, a maioria dos sujeitos não responde o que é avaliação institucional e desconhecem a estrutura organizacional da Secretaria Municipal de Educação.

Palavras-chave: avaliação institucional, Saepe, gestão educacional.
\end{abstract}

\section{INSTITUTIONAL EVALUATION: SOCIALIZATION OF THE STUDY IN THE MUNICIPALITY OF ESCADA/PE}

\begin{abstract}
These studies relate do the Institutional Evaluation theme, specially to the actions developed by the City Educational Department and by the School Managers from the city of Escada/PE regarding the results from Saepe 2014. Our hypothesis starts from the point where the Education Network from Escada/PE, dealing with the results from Saepe 2014, seems to not put forward systematic and progressive actions at schools. The approach is qualitative, the type is descriptive and it was administered at the City Education Department and in two public school. The subjects were two school managers, the city manager and one technician. The instruments for collecting data were documental analyses and semi-structured interviews. The results point the fact that managers have no actions front Saepe results, most of the subjects can't respond to what a Institutional Evaluation means and do not know the organizational structure inside the Education System of the city.

Key-words: institutional evaluation, Saepe, educational management.
\end{abstract}




\section{Introdução}

avaliação é tida como um patrimônio das instituições educacionais. Segundo
Dias Sobrinho (2005), nesse contexto, já se produziu uma extensa literatura,
todavia, não é o caso da avaliação institucional em que no Brasil surgiu como um amplo processo de avaliação do sistema de ensino.

A avaliação institucional tem uma função primordial na organização e gestão dos sistemas escolares e das escolas, pois visa a obter informações e dados quantitativos e qualitativos sobre os alunos, os docentes, a estrutura organizacional e os recursos físicos e materiais (Libâneo, 2013).

Heloísa Lück (2009) apresenta a avaliação como instrumento-chave para o desenvolvimento permanente da qualidade da educação, uma vez que utiliza metodologia científica e informação objetiva para a tomada de decisão e a definição de políticas e práticas pedagógicas. Brandalise (2010) aborda autoavaliação da escola como um processo necessário para compreender a dinâmica institucional a fim de seu desenvolvimento.

Em termos gerais, a realização de avaliações institucionais, enquanto processo diagnóstico de avaliação em larga escala, surgiu no âmbito dos sistemas de ensino como um instrumento ou mecanismo que visa a fornecer informações sobre os processos e resultados da atuação do sistema de ensino a fim de melhorar a qualidade da educação brasileira (Pernambuco, 2011).

O governo de Pernambuco criou o Sistema de Avaliação Educacional de Pernambuco - Saepe -, que tem por objetivo avaliar as escolas municipais e estaduais com relação às habilidades e competências desenvolvidas em língua portuguesa e matemática. O programa avalia estudantes da $2^{\underline{a}}$ série $/ 3^{\circ}$ ano do ensino fundamental em língua portuguesa e da $4^{\mathrm{a}}$ série $/ 5^{\circ}$ ano, $8^{\mathrm{a}}$ série $/ 9^{\circ}$ ano do ensino fundamental e $3^{\circ}$ ano do ensino médio e o normal médio em língua portuguesa e matemática. O Saepe destina-se a diagnosticar a qualidade de ensino, apresentar o desempenho dos alunos, subsidiar e elaborar a reformulação e o monitoramento das políticas educacionais contribuindo para melhoria da qualidade do ensino (Pernambuco, 2011).

O interesse pelo tema avaliação institucional para a educação básica surgiu no de decorrer do estágio supervisionado, quando percebi que pouco se tem discutido, particularmente, em Escada/PE, sobre os resultados gerados pelo Sistema de Avaliação Educacional de Pernambuco. Esses resultados devem ser utilizados pelas instâncias dirigentes para planejar e executar políticas públicas, verificar os sucessos e os insucessos, criar metas de qualidade educacionais, conceber a promoção de mecanismos para formação continuada, implementar novas medidas na elaboração de sua autoavaliação e adequação de seus projetos. Os resultados devem ser socializados por todos os agentes: gerência regional, pela secretaria municipal de educação e por escolas que constitui a rede, daí a urgência do presente trabalho.

A problemática da pesquisa foi expressa nos seguintes termos: quais ações desenvolvidas pelo gestor da Secretaria Municipal de Educação e dos gestores escolares do município da Escada/PE frente aos resultados do Saepe?

A hipótese era a de que a Rede Municipal de Educação da Escada/PE, diante dos resultados do Saepe 2014, parece não promover ações sistemáticas e contínuas nas escolas. 
Assim, se definiu como objetivo geral identificar as ações desenvolvidas pelo gestor da Secretaria Municipal de Educação e dos gestores escolares do município da Escada/PE frente aos resultados do Saepe 2014. Os objetivos específicos foram: investigar o que o Gestor Municipal e os Gestores Escolares entendem por avaliação institucional; verificar se no Plano Municipal de Educação (PME) e dos gestores escolares consta ações frente aos resultados apresentados no Saepe como soluções aos problemas apresentados.

A abordagem da pesquisa foi qualitativa e descritiva. Os instrumentos de coleta foram a entrevista semi-estruturada e análise documental. $O$ campo de investigação foi a Secretaria de Educação de Escada e duas escolas da rede pública municipal de ensino de Escada/PE e os sujeitos foram o gestor municipal, dois gestores escolares e uma técnica municipal responsável pelos processos de avaliação e monitoramento.

\section{Avaliação institucional}

Ao tratarmos de avaliação institucional cabe um retrospecto sobre o conceito de avaliação que é, portanto, um instrumento processual que visa à coleta de elementos e informações quantitativa, realização de uma análise crítica e proporciona a tomada de decisões para transformação de um processo, evento ou fato. Instrumento processual esse que pode fornecer variados contextos, com as mais variadas significações e com os mais variados objetivos.

Segundo Lück (2012)

a avaliação é um processo de inquirição, observação e coleta de dados, registro, análise e interpretação da realidade, realizado com o objetivo de conhecê-la, para dar-lhe encaminhamento mais efetivo. A avaliação é própria das ações intencionais de investigação e inerente a elas, e se constitui na adoção de métodos por questionamentos e envolve inquirir, perguntar, investigar. (p. 37)

A avaliação envolve diferentes etapas: recolhimento de informações ou produção de informações determinada realidade; análise e interpretação do cenário a ser avaliado e a emissão de tomada de decisão; exposição do que precisa ser feito; encaminhamento de possíveis soluções. Sendo assim, a avaliação é um processo realizado por diversos instrumentos, dentre eles destacam-se a observação, registros, provas entre outros.

Pernambuco (2012) apresenta um esquema com os tipos de avaliação. 
Figura 1 -

Esquematização dos tipos de avaliação.

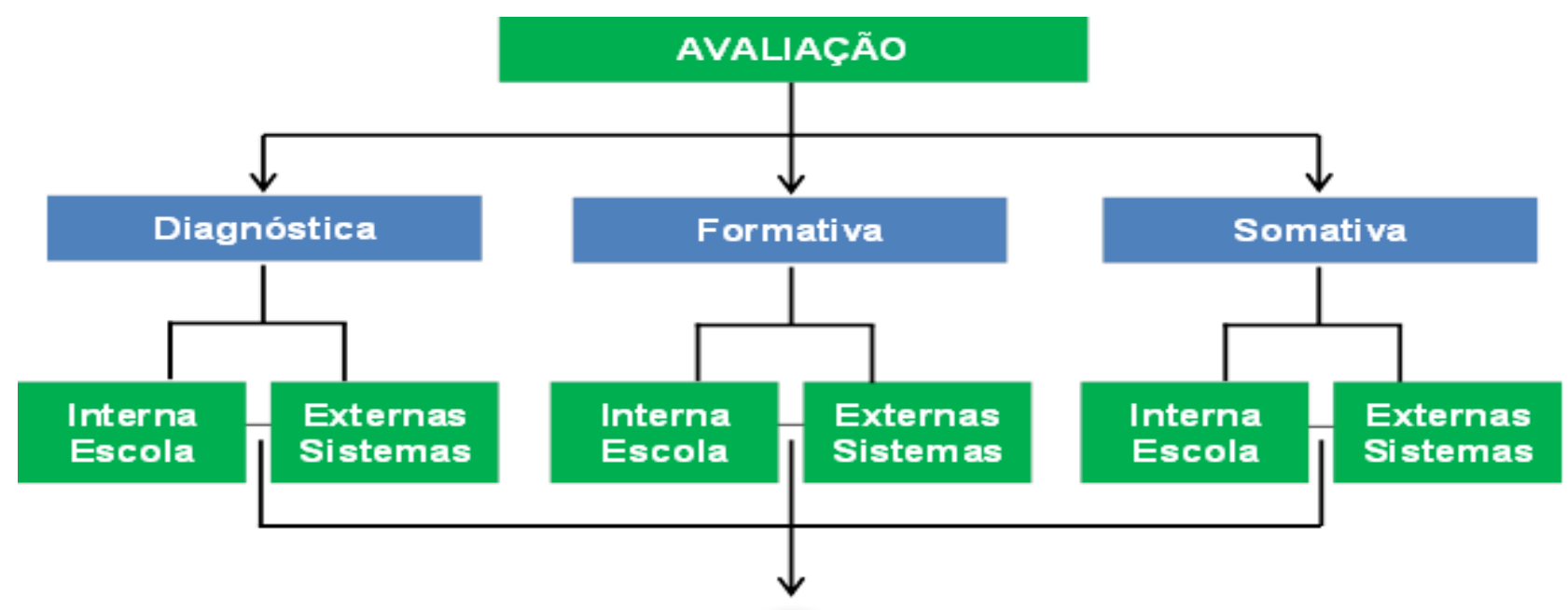

Pequena Escala | Larga Escala

Fonte: Pernambuco (2012, p. 8)

A avaliação diagnóstica é um processo de sondagem ou retrospecção situacional do desenvolvimento do aluno, processo que têm elementos a fim de verificar o que aprendeu e como aprendeu. Segundo (Santos, 2007) "é uma etapa que tem por objetivo verificar em que medida os conhecimentos anteriores ocorreram e o que se faz necessário para selecionar dificuldades encontradas" (p. 4). A avaliação diagnóstica figura como um processo essencial no processo de ensino-aprendizagem.

A avaliação formativa acontece durante a etapa ou unidade do processo de ensinoaprendizagem. É uma metodologia que proporciona a tomada de decisões adequada à mudança e que segundo Sanmartí (2009) visa a regular a aprendizagem dos discentes.

A avaliação somativa acontece pela certificação da aprendizagem dos discentes na finalização de uma etapa ou unidade do processo de ensino-aprendizagem. Para (Sanmartí, 2009) a avaliação somativa tem objetivo de selecionar, ou seja, conferir socialmente essa certificação.

Esses tipos de avaliações podem ser realizados em formas e escalas diferentes, ou seja, tanto internamente pelas as avaliações formais realizadas por agentes que são próprio do contexto avaliativo, ou externamente, quando promovidas por agentes extrínsecos a instituição, assim como podem ser realizadas em pequena ou larga escala.

O conceito de avaliação institucional apresenta diferentes significações. Para Lück (2012) a avaliação institucional "consiste em um processo sistemático, abrangente e contínuo de observação, coleta e análise de dados, interpretação e julgamento da realidade e práticas escolares, em seus desdobramentos e interações, tendo em por finalidade contribuir para a melhoria do trabalho educacional e seus resultados" (p. 39).

Para Libâneo (2013) a avaliação institucional é

uma função primordial do sistema de organização e gestão dos sistemas escolares e das escolas. Essa avaliação, também chamada de administrativa, visa à obtenção de dados quantitativos e qualitativos sobre 
os alunos, os professores, a estrutura organizacional, os recursos físicos e materiais, as práticas de gestão, a produtividade dos cursos e dos professores etc., com o objetivo de emitir juízos valorativos e tomar decisões em relação ao desenvolvimento da instituição. (p. 198)

A avaliação institucional, para Afonso (2009), é uma organização que envolve a instituição como um todo, em que não é possível avaliar institucionalmente apenas por resultados de avaliação externas, mas, sim perpassando pelos fatores intra e extra da instituição.

Segundo Dias Sobrinho (2005) a avaliação institucional e "reafirma o sistema de valores dominante da instituição: valores fundamentalmente de caráter científico e pedagógico. Como produção social, autônoma e pública, esse processo não pode ser senão democrático. [...] A avaliação Institucional revitaliza o exercício da democracia" (p. 34).

A avaliação institucional, como processo de autoconhecimento na totalidade no que se refere à gestão, a infraestrutura e outros segmentos, é a etapa de verificação identidade própria da instituição de ensino e envolve autoconhecimento, processo de autoavaliação, construção coletiva, feedback, processo de transformação, processo aberto e contextualizado e como responsabilidade e prestação de contas.

A avaliação institucional como processo de autoavaliação subordina-se ao autoconhecimento que, segundo (Lück, 2012) é um processo de planejamento para implementação da avaliação na organização que com a análise e os desdobramentos dos resultados é possível traçar metas e reformular as práticas visando à melhoria.

A avaliação institucional, como construção coletiva, acontece pela participação efetiva de todos os agentes, tais como: gestor, funcionários, professores, alunos, pais e comunidade atuando de forma integrada nos processos de construção coletiva para o desenvolvimento organizacional.

A avaliação institucional, como feedback, é um "processo de retorno e reflexão sobre os dados e informações gerados sobre o desempenho de uma ação a fim de reorientar para que essa ação ocasione melhorias de desempenho" (Lück, 2012, p. 53), assim como "é plenamente útil quando resulta não somente em melhorias das práticas educacionais, mais em transformações de modos de ser e de fazer na escola" sendo para (Lück, 2012, p. 58).

A avaliação institucional caracteriza-se como um processo estratégico de "prospecção, construção de conhecimento e acompanhamento do trabalho realizado, em seus desdobramentos e detalhes, de modo a permitir a tomada de decisão apoiada objetivamente" segundo (Lück, 2012, p. 41) a fim de promover o desenvolvimento institucional da escola.

Ainda segundo (Lück, 2012) os principais objetivos para a realização da avaliação institucional são

1) desenvolver uma cultura de avaliação na escola, marcada por reflexão crítica pelos participantes da comunidade escolar sobre a sua atuação específica e respectiva repercussão no trabalho escolar como um todo; 2) criar bases objetivas de construção e atualização contínua da política educacional da escola, expressa na elaboração do seu projeto político pedagógico; 3) prestar contas, de maneira clara e transparente, aos pais, à 
comunidade, à sociedade e a mantenedores, de como a escola atua e como realiza os seus objetivos sociais; 4) estabelecer compromissos com a comunidade escolar para a superação da limitações e alcance de estágios mais avançados de desenvolvimento; 5) contribuir para formação objetiva da identidade da escola, a partir de suas ações e contribuições. (p. 77)

Nesse contexto, o desenvolvimento da avaliação institucional é conduzido por princípios básicos e norteadores: abrangência, comparabilidade, continuidade, legitimidade, objetividade, proatividade, relevância, senso de oportunidade, sigilo e ética e transparência (Lück, 2012).

O princípio da abrangência é a integração dos elementos e aspectos avaliados em uma visão global podendo ser incorporado nos elementos. A comparabilidade é a confrontação dos dados externos e dos dados obtidos internamente, ou podendo comparar com outra escola ou sistema de ensino. A continuidade é o processo de caráter evolutivo, sistemático de avaliação e superação das dificuldades. A legitimidade dar-se pela autonomia da instituição e pela participação da comunidade no processo de análise e aplicabilidade dos resultados. A objetividade visa caracterizar a realidade tal como é, e não como julga que seja. A proatividade dar-se pelo acompanhando e monitoramento dos problemas e desafios tendo em a construção da visão de futuro. A relevância é que os dados e as informações sejam úteis para orientação da melhoria institucional. O senso de oportunidade é a etapa de interpretação de dados e de tomada de decisões. O sigilo e a ética é um processo de não-premiação ou punição valendo-se dos princípios éticos e a transparência é prestação de conta a comunidade (Lück, 2012).

A avaliação institucional é um processo de fundamental realização nas instituições de ensino tendo em vista a verificação a fundo do cenário interno e externo e obtenção de dados que deve ser utilizado para melhoria da educação, seguindo um caráter de global, reflexivo, emancipação, continuidade e de prestação de contas à comunidade escolar.

\section{O sistema de avaliação de pernambuco}

O Sistema de Avaliação Educacional de Pernambuco - Saepe - é um programa que tem por objetivo de avaliar as escolas municipais e estaduais e verificar a qualidade e 0 desempenho das instituições de ensino, a fim de fornecer incentivos de melhorias ao sistema e desenvolve um trabalho de monitoramento da rede. As provas são realizadas a cada dois anos nas escolas estaduais e em escolas municipais, que realizam a adesão ao sistema. Foi implantado no ano de 2000 em parceria com a Universidade Federal de Juiz de Fora.

O Saepe é composto por cincos objetivos:

a) produzir informações sobre o grau de domínio dos estudantes nas habilidades e competências consideradas essenciais em cada período de escolaridade avaliado. estes são pré-requisitos indispensáveis não apenas para a continuidade dos estudos, mas para a vida em sociedade; b) monitorar o desempenho dos estudantes ao longo do tempo, como forma de avaliar continuamente 0 projeto pedagógico de cada escola, possibilitando a implementação de medidas corretivas quando necessário; c) contribuir diretamente para a adaptação das práticas de ensino às necessidades dos alunos, diagnosticadas por meio dos instrumentos de avaliação; d) associar os resultados da avaliação às políticas de incentivo 
coma intenção de reduzir as desigualdades e elevar o grau de eficácia da escola; e) compor, em conjunto com as taxas de aprovação verificadas pelo censo escolar, o Índice de Desenvolvimento da Educação Básica de Pernambuco - Idepe. (Pernambuco, 2002, p. 4)

O Plano Estadual de Educação de Pernambuco destaca que a criação de um sistema de avaliação próprio permite obter um diagnóstico dos níveis de aprendizagem dos alunos em cada escola, das demandas de formação continuada no Estado em observação às deficiências e das potencialidades da rede de ensino e para subsidiar ações de formação continuada mais eficazes, voltadas para as necessidades reais da escola (Pernambuco, 2002).

O Sistema de Avaliação Educacional de Pernambuco contempla duas dimensões: a de desempenho dos docentes da rede e a de fatores externos associados a tal desempenho de proficiência, se utilizando de testes e questionários a fim da verificação da proficiência dos discentes e os fatores contextuais que se entrelaçam a fim de subsidiar a melhoria do cenário educacional.

Pelo Saepe busca-se verificar a relação das habilidades e competências desenvolvidas pelos estudantes em língua portuguesa e matemática. O programa avalia

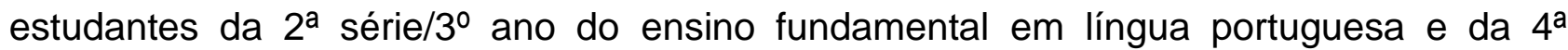

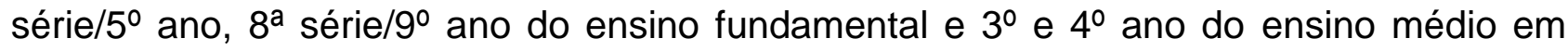
língua portuguesa e matemática: "O Saepe constitui-se numa avaliação padronizada e censitária que permite aferir o desempenho dos estudantes em Língua Portuguesa e Matemática no $3^{\circ}, 5^{\circ}$ e $9^{\circ}$ ano do ensino fundamental e $3^{\circ}$ ano do ensino médio incluindo os projetos de correção do fluxo escolar (Pernambuco, 2012, p. 23).

A matriz de referência do Saepe apresenta o objeto dos testes, formado por um conjunto de habilidades, tido por descritores que é construído segundo as propostas curriculares de cada área de conhecimento e etapa de escolaridade.

A teoria de resposta ao item - TRI - é um modelo estatístico que pode produzir informações sobre as características dos itens utilizados em testes. Segundo (Andrade, 2011) "é um conjunto de modelos matemáticos que procura representar a probabilidade de um indivíduo dar certa resposta a um item como função dos parâmetros do item" ( $p$. 11), essencial para as avaliações de larga escala e provas diagnósticas.

O Saepe possui uma escala de proficiência própria, definida em quatro categorias: Elementar I, Elementar II, Básico e Desejável:

A categoria elementar I é um padrão de desempenho em que os estudantes nessa etapa apresentam competências e habilidades insuficientemente ao que era esperado no período de escolarização. A categoria elementar II é um padrão de desempenho em que os estudantes apresentam um domínio inicial e um processo sistemático das habilidades básicas e essenciais no período de escolarização. A categoria básica é um padrão de desempenho que os estudantes apresentar um leque ampliado de habilidades no período de escolarização. A categoria desejável é um padrão de desempenho em que os estudantes demonstram ser capazes de realizar tarefas que requeiram complexas habilidades e supera as habilidades esperadas no período de escolarização. (Pernambuco, 2011, p. 49) 
O Sistema de Avaliação Educacional de Pernambuco se utiliza, para obtenção dos dados, de uma avaliação para os estudantes e um questionário contextual aplicado, online, aos os estudantes e diretores escolares, professores, coordenadores da gerencias regionais e funcionários das secretarias de educação.

Além da aplicação dos testes, a avaliação inclui outros instrumentos importantes, como: o questionário do estudante, cujo objetivo é traçar seu perfil socioeconômico e sua trajetória escolar; os questionários do professor e do diretor, com o objetivo de traçar o perfil dos profissionais da educação de Pernambuco; e o questionário da escola, cuja finalidade é conhecer infraestrutura e os serviços oferecidos por ela, tendo-se em vista identificar os fatores que interferem no desempenho escolar.

Os questionários contextuais, segundo (Pernambuco, 2012), são tidos como importantes

para a avaliação da educação, pois as políticas administrativas e pedagógicas se pautam pelos resultados de sua escola, e esse instrumento nos ajuda a entendê-los. O correto preenchimento e a fidedigna aferição dos resultados do questionário contextual são fundamentais, de modo que se possam tomar medidas que melhorem as práticas no espaço escolar. (p. 16)

Figuram como sendo fatores intraescolares a gestão e administração escolar, a prática pedagógica, as condições de infraestrutura e a qualificação dos profissionais e fatores extraescolares: os fatores socioeconômicos, fatores familiares e os fatores individuais (Pernambuco, 2012).

Figura 2 -

Instrumentos da avaliação do Saepe.

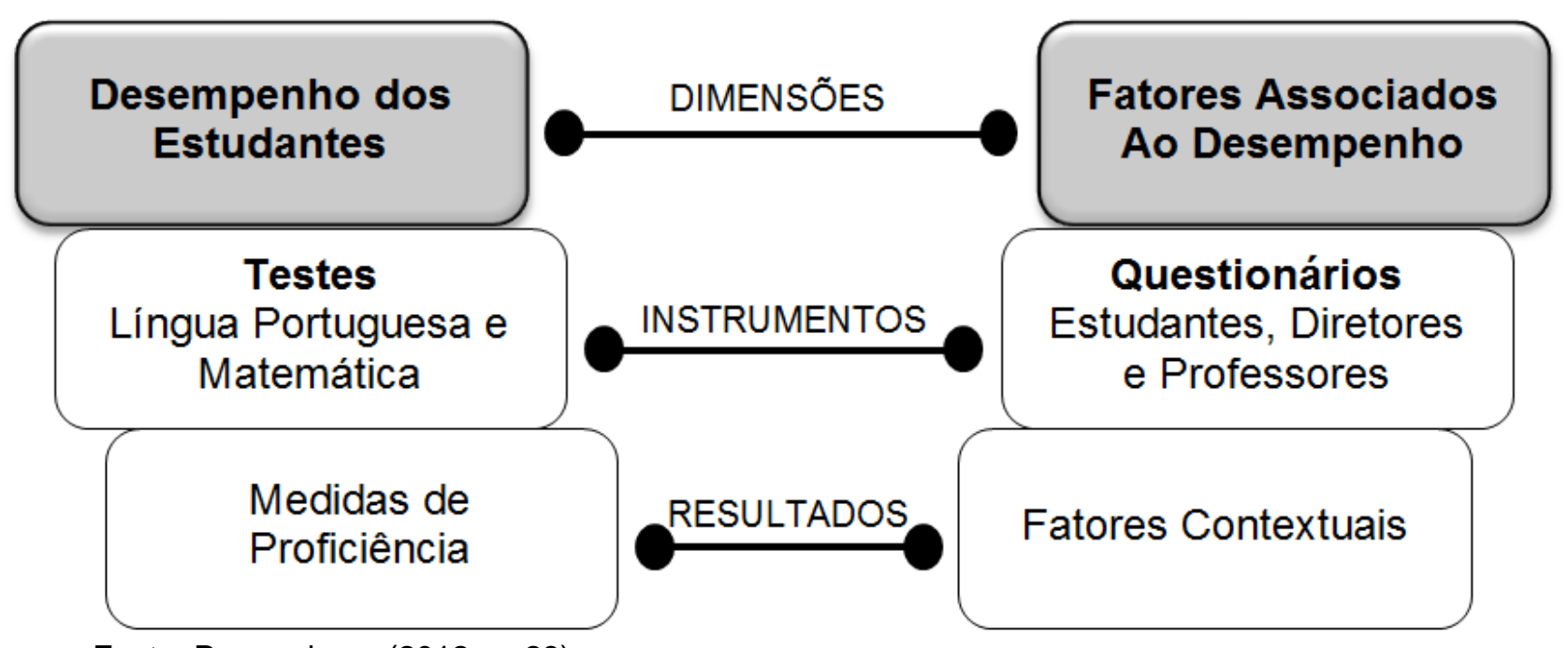

Fonte: Pernambuco (2012, p. 28).

A aplicação dos resultados do Saepe visa a uma perspectiva macro na dimensão de implantação de politicas públicas e uma perspectiva micro na dimensão de prática pedagógica, concebendo assim a equidade dos processos educacional, a melhoria e a 
qualidade da educação. Proporciona informações para a tomada de decisões, para o fornecimento de intervenções pedagógicas e para a prestação de contas.

Os resultados para a escola são disponibilizados por meio de boletins pedagógicos, que contém os resultados por escola e as orientações para os professores e equipes gestora e técnica a fim da melhoria da qualidade quanto à oferta dos serviços educacionais disponibilizados pela rede pública estadual de ensino. É a partir desse sistema que se realiza o diagnóstico da aprendizagem, da estrutura física da rede, suas potenciais e deficiências a fim de subsidiar a promoção de ações articuladas na formação do corpo docente e direcionada as necessidades do sistema de ensino.

Vale ressaltar que o Índice de Desenvolvimento da Educação de Pernambuco Idepe - é o indicador de qualidade da educação pública estadual que permite diagnosticar e avaliar a evolução de cada escola anualmente. $O$ cálculo do Idepe considera o fluxo escolar e a média do desempenho dos estudantes na avaliação do Saepe verificando a proficiência em Língua Portuguesa e Matemática.

\section{A avaliação no município de Escada/PE: organização da rede e funcionamento}

O Sistema Municipal de Ensino da Escada/PE foi instituído pela lei n. 2.234, de 12 de dezembro de 2008. Tem 16 escolas municipais na área urbana, em cada uma tem um gestor que responde pela escola. Na área rural tem 32 escolas que estão distribuídas em três subsetores e são acompanhadas por um gestor, um secretário e um coordenador pedagógico.

Figura 3 -

Subsetores organizacionais.

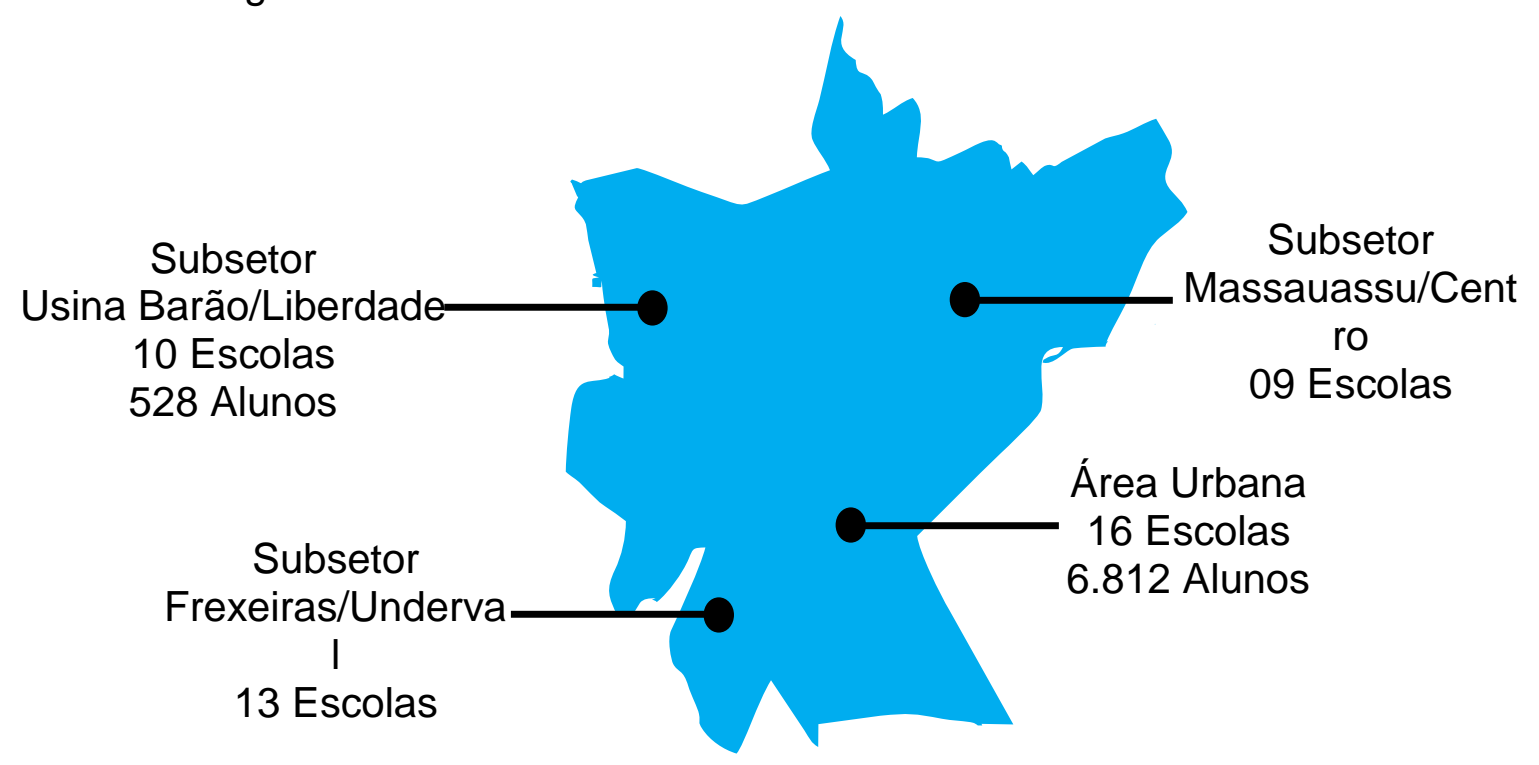

Fonte: Dados da pesquisa (2016).

Para avaliar os resultados da aprendizagem destas escolas a Secretaria de Educação criou o Núcleo de Avaliação da Aprendizagem Interna e Externa, que tem por finalidade subsidiar o processo de ensino e aprendizagem nas instituições e escolas que atendem ao público da educação infantil e anos iniciais e finais do ensino fundamental. O núcleo tem por objetivo: a) orientar o monitoramento do Sistema de Avaliação Educacional de Pernambuco - 
Saepe; b) produzir informações sobre as habilidades e competências dos estudantes consideradas essenciais no período de escolaridade avaliada; c) contribuir diretamente para adaptação das práticas pedagógicas; d) monitorar o desempenho dos estudantes durante o processo de ensino/aprendizagem; e) observar as necessidades dos alunos diagnosticadas por meios dos instrumentos de avaliação; f) compor um banco de dados em conjunto com as taxas de aprovação verificadas pelo censo escolar e pelo Índice de Desenvolvimento da Educação de Pernambuco - Idepe; g) divulgar a realização e os resultados da Prova Brasil.

O Regulamento do Sistema de Avaliação da Aprendizagem nas Escolas da Rede Municipal de Ensino da Escada/PE trata dos seguintes elementos: orientações pedagógicas da avaliação; ao processo de progressão do estudante; aos procedimentos de atribuição e registro de notas; a recuperação da aprendizagem; aos registros da avaliação das aprendizagens e apresentação de informações gerais quanto à sistemática da avaliação da aprendizagem.

A formação dos colaboradores acontece por meio de treinamento para os coordenadores regionais e municipais do Saeb/Saepe, o qual acontece segundo convocação por meio de ofício circular da Gerência de Avaliação e Monitoramento das Políticas Educacionais da Secretaria Estadual de Educação encaminhado pelas regências regionais de educação aos seus municípios jurisdicionados, informando-lhes a programação.

As avaliações em Escada/PE ocorrem a partir da formação com gestores, supervisores da área rural e coordenadores; formação na GRE para alinhamento do censo rápido; estudo da base do Saeb/Saepe para alinhamento das escolas e distribuições dos coordenadores de turmas; alocação do coordenador do polo e adesão da prefeitura; visitas e ligações para as escolas com o objetivo de alinhar as crianças com necessidades (turmas do AEE) que irão fazer avaliação; preenchimento da plataforma para realização do curso de alinhamento da Prova Brasil. online; alinhamento da base da Prova Brasil; estudo dos resultados do Idepe e divulgação para os gestores da Secretaria de Educação; pesquisa e resposta de questionário enviado pela GRE para sondar referências que os gestores utilizam para organizar o trabalho pedagógico, as dificuldades de adaptações curriculares e as avaliações municipais; preenchimento da planilha com dados da Secretaria de Educação para adesão do município nas avaliações externas.

A Secretaria Executiva de Educação da cidade de Escada/PE, não dispõe de um sistema de avaliação próprio com legislação especifica, entretanto, para realizar a sua avaliação institucional necessita de subsídio da Secretaria Estadual de Educação e de suas regências regionais. Os resultados obtidos servem para planejar ações. A partir daí os técnicos educacionais convocam todos os gestores escolares da rede municipal de educação para participarem de formação continuada e traçam plano de ação individual e coletivo a fim de melhorar o rendimento da aprendizagem para a próxima avaliação. 0 município atende as diretrizes para aplicar e coletar os cadernos de provas e com os resultados planeja as seguintes ações: 1) utilizar eficientemente os dados oriundos dos distintos procedimentos de avaliação federal e estadual do sistema educacional, de modo a permitir a reflexão da comunidade interna e externa à escola, bem como o planejamento de ações factíveis de aprimoramento pedagógico. Para tanto elaboramos um plano de ação com os gestores e coordenadores das escolas; 2) negociar com a comunidade escolar metas educacionais factíveis de alcance em um dado período de tempo. A terceira ação foi reconhecer publicamente $\mathrm{o}$ alcance das metas estabelecidas, através de incentivos à 
comunidade escolar, apresentamos as escolas os resultados e as melhores proficiências. Um incentivo foi proporcionar formação continuada aos gestores e aos professores das escolas para que alcance as metas e/ou no incremento dos valores do Ideb/ldepe; 3) aproximação das famílias das escolas por meio de palestras nas escolas e visitas técnicas, as quais proporcionam a comunidade o sentimento de pertencimento do processo educacional. 4) promoção de atividades que favorece o conhecimento das questões das avaliações foram distribuídos para as escolas cd's com modelos das provas para os educadores apliquem nas escolas. As famílias devam participar ativamente deste novo modelo educacional, acompanhando os alunos, negociando metas educacionais e cobrando melhores resultados nas avaliações externas; melhores alunos deverão ser inseridos na formação de seus pares, através de ações de monitoria pretende-se neste ano letivo, incentivar ainda mais a aprendizagem dos educandos de Escada/PE.

\section{Local de investigação}

A pesquisa foi realizada em duas escolas da área rural pertencentes a rede pública municipal de ensino da cidade de Escada/PE, denominadas de Escola $A$ e $B$.

Escola A - escala de desempenho: Desejável - localizada na zona rural do Município

de Escada/PE, especificamente no Engenho Braço do Meio, de dependência administrativa municipal e dispõe do Programa Mais Educação e de um projeto de leitura.

Essa instituição de ensino oferta curso da educação básica que funciona em dois turnos distintos: um no período matutino, das 7h30min às 11h30min com educação infantil, anos iniciais do ensino fundamental, e outro no período noturno, das $19 \mathrm{~h}$ às $21 \mathrm{~h}$ com a I e II fase da educação de jovens e adultos.

A unidade educacional dispõe em sua estrutura física de três salas de aulas, uma cozinha, um almoxarifado, dois banheiros, um laboratório de informática e uma área interna de recreação. O corpo discente é composto 44 alunos, o corpo docente por três professores e o corpo administrativo e auxiliar é formado por um coordenador pedagógico e duas merendeiras. A escola possui projeto político pedagógico e não realiza reuniões com pais e mestres.

Escola B - escala de desempenho: Elementar I, localizada na zona rural do Município de Escada/PE, especificamente no Engenho Noruega, situada em um prédio sem estrutura na jurisdição entre a cidade de Escada e Cabo de Santo Agostinho/PE e dispõe do Projeto ação saudável.

A instituição oferta curso da educação básica e funciona num único turno no período vespertino, das $12 \mathrm{~h}$ às $16 \mathrm{~h}$, com turmas duas turmas, sendo uma de educação infantil e outra do $1^{\circ}$ ao $5^{\circ}$ ano do ensino fundamental: todas as turmas são organizadas na forma multisseriada.

A unidade educacional dispõe em sua estrutura física com duas salas de aulas, uma cozinha e um banheiro. O corpo discente é composto por 20 alunos, o corpo docente é composto por duas professoras e o corpo administrativo e auxiliar é formado por uma coordenadora pedagógica e uma merendeira. A escola possui projeto político pedagógico e realiza duas reuniões pedagógicas mensais com pais, mestres e uma comissão de acompanhamento a fim de discutir o desempenho dos alunos. 
A escolha das escolas ocorreu a partir do componente curricular Matemática que verificamos a escala de proficiência nas turmas de $5^{\circ}$ ano (4⿳亠丷厂 série) ensino fundamental. Comparamos a média de desempenho das escolas em todo o Sistema de Educação Municipal de Escada/PE e optamos por duas escolas que apresentam à menor e a maior escala de proficiência do município.

Os sujeitos deste estudo foram duas gestoras de escolas públicas rurais da educação básica e uma técnica educacional do Departamento de Avaliação e Monitoramento e a secretária municipal de educação da cidade de Escada/PE. Para a realização da pesquisa foi considerados os seguintes instrumentos de coleta de dados: uma entrevista semi-estruturada e análise documental.

A análise realizada nos planos de ação dos gestores das escolas $A$ e $B$ revelam que não há ações que contemplem a avaliação institucional nos aspectos da estrutura física $e$ material, recursos financeiros, de pessoal e organizacional a fim da melhoria da qualidade da instituição de ensino.

Quanto às ações desenvolvidas pelos gestores frente aos resultados do Saepe verifica-se que a única ação é trabalhar os descritores de forma detalhada dos componentes curriculares de Língua Portuguesa e Matemática em um turno e no contra turno realizando atividades referentes às avaliações do Saepe e Saeb.

O Plano de ação dos gestores escolares foi elaborado pela Secretaria de Educação, um plano de caráter unificado para que toda a rede de ensino que objetiva a promoção de intervenções pontuais para solucionar impasses de ordem pessoal, administrativo, pedagógico e de logística. A avaliação do plano de ação acontece de forma contínua e na perspectiva de uma visão construtivista, priorizando os princípios de eficácia e eficiência não levando em consideração o caráter autônomo da escola.

Inicialmente buscamos compreender a concepção de avaliação institucional para cada sujeito, ou seja, questionamos os sujeitos perguntando o que é avaliação institucional? As respostas foram as seguintes:

É a avaliação que dá o diagnóstico do trabalho desenvolvido com os alunos a nível municipal, estadual e federal. (G1)

Avaliação institucional é uma implantação do sistema municipal como uma tendência de politicas educacionais que potencializa a qualidade da educação. (G2)

A avaliação institucional foi criada no dia 14 de abril de 2004, com o objetivo de acompanhar e avaliar o ensino-aprendizagem tanto em nível nacional como estadual. Portanto ela esta dividida em duas modalidades: a avaliação interna que é a autoavaliação e a avaliação externa que são as provas que vem do governo federal e estadual para ser aplicadas nas escolas e estaduais e municipais para acompanhar a aprendizagem dos alunos. (TE)

Avaliação institucional ela tem o papel fundamental de avaliar as ações dentro sistema institucional e ela promove um diagnóstico de rede de como o processo educacional está sendo recebido, construído por essa rede da educação municipal de Escada/PE. (SM) 
Analisando os relatos dos sujeitos sobre a avaliação institucional se percebe que para o gestor 1 a avaliação institucional é aquela que "dá o diagnostico do trabalho desenvolvido com os alunos a nível municipal, estadual e federal" (G1). Ou seja, tem uma visão com foco na avaliação da aprendizagem e não consegue perceber que a avaliação.

O gestor 2 percebe a avaliação institucional como sendo "uma implantação do sistema municipal deixando de lado os outros entes federados sendo considerada pela mesma como uma tendência de politicas educacionais que potencializa a qualidade da educação, em suma a avaliação institucional tem essa funcionalidade." O gestor G2 desprende-se ainda da característica sistemática, de observação, coleta e análise de dados, interpretação e julgamento da avaliação institucional, logo esse gestor não conceitua o que é avaliação institucional.

Nossa análise revela que para a técnica (TE) o objetivo da avaliação institucional é acompanhar e avaliar o ensino-aprendizagem, tanto em nível nacional, quanto estadual, respondendo parcialmente. TE entende a avaliação institucional como sendo criada pela legislação que estabelece o Sistema Nacional de Avaliação da Educação Superior Sinaes.

Do relato da secretaria municipal (SM) sobre a avaliação institucional depreende-se que esta tem o papel de avaliar as ações dentro sistema institucional e também de promover um diagnóstico de rede de forma a conceber a verificação de como o processo educacional está sendo recebido e construído por essa rede da educação municipal.

No geral, as análises das entrevistas mostraram que são múltiplas as concepções dos sujeitos sobre a definição de avaliação institucional devido a sua formação acadêmica e quanto a suas vivências e experiências na área de gestão educacional. Podemos depreender, frente aos relatos, que a maioria dos sujeitos não responde o que é avaliação institucional e até apresenta definições não consistentes mais que representam fragmentos característicos da avaliação institucional.

\section{Considerações finais}

O objetivo desta investigação foi investigar as ações desenvolvidas pelo gestor da Secretaria Municipal de Educação e dos gestores escolares do município da Escada/PE frente aos resultados do Saepe no ano 2014. A pesquisa revelou apenas um plano de ação elaborado pela técnica educacional do Núcleo de Avaliação da Aprendizagem Interna e Externa da Secretaria de Educação Municipal, a ser desenvolvido por todas as escolas do sistema municipal de ensino, com o objetivo de trabalhar ações integradas para realizar com sucesso na avaliação externa à escola.

Em relação à concepção de avaliação institucional do gestor municipal e dos gestores escolares os dados apontam que a maioria dos sujeitos não conceitua o que é avaliação institucional, mas apresentam fragmentos de características da avaliação institucional.

Conclui-se que o Plano Municipal de Educação do Sistema Municipal de Educação da Escada/PE elenca metas e estratégias que contemplem a avaliação e o monitoramento, a prática sistemática da avaliação institucional no sistema de ensino e nas instituições de ensino, mas não prevê ações.

Os planos de ação dos gestores das escolas A e B foram elaborados pela Secretaria de Educação Municipal a ser desenvolvidos nas escolas e constam com a finalidade de 
realizar com sucesso a avaliação externa. Portanto, se torna urgente a reestruturação desses planos de ação, considerado as necessidades da escola e, em particular, os resultados do Saepe a fim da melhor a qualidade da instituição de ensino. Ressalto a confirmação da hipótese, tendo evidências de que a rede municipal de educação da Escada/PE ainda não promove ações sistemáticas e contínuas nas escolas.

Assim, ao término desta pesquisa, esperamos que as discussões e as análises empreendidas nesse estudo colaborem para o aprofundamento dos debates em torno da avaliação institucional externa e da sistemática da prática pedagógicas a partir dos resultados do Saepe para a gradativa mudança nos processos gestores das instâncias e instituições de ensino.

\section{Referências}

AFONSO, Almerindo Janela. Avaliação educacional: regulação e emancipação: para uma sociologia das políticas avaliativas contemporâneas. São Paulo: Cortez, 2009.

ANDRADE, Renato Júdice de (org.). Avaliação de competências na educação básica: um marco referencial para a prática. São Paulo: Moderna, 2011.

BRANDALISE, Mary Ângela Teixeira. Avaliação institucional da escola: conceitos, contextos e práticas. Revista Olhar de Professor, Universidade Estadual de Ponta Grossa, Departamento de Métodos e Técnicas de Ensino, Ponta Grossa, v. 13, n. 2, p. 1-16, 2010.

BRASIL. Constituição Federal, 1988.

BRASIL. Lei n. 9.394, de 20 de dezembro de 1996. Estabelece as diretrizes e bases da educação nacional. Diário Oficial da União, 23 dez. 1996.

DIAS SOBRINHO, José; BALZAN, Newton César. Avaliação institucional: teoria e experiência. São Paulo: Cortez, 2005.

ESCADA. Lei n. 2.439, de 22 de junho de 2015. Dispõe sobre o alinhamento do Plano Municipal de Educação para o Decênio 2015-2025. Escada, 22 jun. 2015.

LIBÂNEO, José Carlos. Organização e gestão da escola: teoria e prática. São Paulo: Heccus Editora. 2013.

LÜCK, Heloísa. Dimensões de gestão escolar e suas competências. Curitiba: Positivo, 2009.

LÜCK, Heloísa. Perspectivas da avaliação institucional da escola. Petrópolis: Vozes, 2012.

LÜDKE, Menga Alves; MARLI, Eliza Dalmazo André. Pesquisa em educação: abordagens qualitativas. São Paulo: EPU, 1986.

PERNAMBUCO. Nota técnica: a avaliação das escolas estaduais e o bônus de desempenho educacional - BDE. Recife: Secretaria de Estado da Educação e cultura, 2002.

PERNAMBUCO. Secretaria de Educação. Saepe 2011. Juiz de Fora: UFJF, 2011.

PERNAMBUCO. Construindo a excelência em gestão escolar: curso de aperfeiçoamento Módulo XI - Monitoramento e avaliação dos processos de ensino e aprendizagem. Recife: Secretaria de Educação do Estado, 2012. 
PRODANOV, Cleber Cristiano. Metodologia do trabalho científico [recurso eletrônico]: métodos e técnicas da pesquisa e do trabalho acadêmico. Novo Hamburgo: Feevale, 2013.

SANMARTÍ, Neus. Avaliar para aprender. Porto Alegre: Artmed, 2009.

SANTOS, Monalize Rigon dos; VARELA, Simone. A avaliação como um instrumento diagnóstico da construção do conhecimento nas séries iniciais do ensino fundamental. Revista Eletrônica de Educação, ano I, n. 1, 2007, p. 29-42.

Aldemir Lima da Silva Junior é especialista em gestão educacional com ênfase em recursos humanos.

Endereço: Segunda Travessa São José, 105 - Escada - PE - Brasil.

E-mail: aldemirlima@hotmail.com.br.

Valderês Conceição do Monte é mestre em ensino das ciências.

Endereço: Rua do Jangadeiro, 1320/207, bloco C - Jaboatão dos Guararapes - PE Brasil.

E-mail:vcmontes1960@gmail.com.

Recebido em 13 de março de 2017.

Aceito em 21 de junho de 2017. 